\title{
ANALISIS KEBUTUHAN SISWA DALAM MATERI BUKU TEKS BAHASA INGGRIS TINGKAT SMK
}

\author{
${ }^{1)}$ Sri Supiah Cahyati, ${ }^{2)}$ Cynantia.R, S., ${ }^{3)}$ Siska Rizkiani \\ ${ }^{1)}$ srisupiahcahyati02@gmail.com, ${ }^{2)}$ cynan_tia@yahoo.com, ${ }^{3)}$ siska.rizkiani@gmail.com \\ ${ }^{1,2,3)}$ Program Studi Pendidikan Bahasa Inggris, STKIP Siliwangi
}

\begin{abstract}
ABSTRAK
Pembelajaran bahasa Inggris di Sekolah Menengah Kejuruan (SMK) berbeda dengan pembelajaran bahasa Inggris di Sekolah Menengah Umum lainnya. Di SMK, orientasinya adalah mempersiapkan siswa agar mampu berkiprah di dunia kerja. Melihat fenomena di atas, guru-guru Bahasa Inggris di SMK diharapkan memiliki kemampuan dalam menganalisis kebutuhan siswa sehingga mereka dapat merancang proses belajar- mengajar yang sesuai, terutama dalam keterampilan berbahasa Inggris (Listening, Speaking, Reading, dan Writing) dan komponen dalam bahasa Inggris (Grammar \& Vocabulary). Tujuan dari penelitian ini adalah untuk mengidentifikasi beberapa informasi faktual mengenai kebutuhan siswa SMK dalam pembelajaran bahasa Inggris,.dan menganalisis kesesuaian antara kandungan dalam buku teks pelajaran Bahasa Inggris dengan siswa di SMK dari segi kebutuhan siswa (students' needs). Subjek yang diteliti adalah siswa SMK dan buku pelajaran bahasa Inggris, baik edisi KTSP maupun edisi Kurikulum 2013, dari 7 (tujuh) SMK yang menyelenggarakan jurusan TKJ di daerah Bandung dan Cimahi. Hasil menunjukkan kebutuhan siswa terhadap pembelajaran bahasa Inggris adalah untuk memenuhi kebutuhan profesi akademik dan masa depan siswa, yang melibatkan kemampuan bahasa dan beberapa komponen bahasa. Sedangkan dalam hal kesesuaian antara kandungan dalam buku teks bahasa Inggris dengan jurusan siswa di SMK TKJ dari segi students need, hasil menunjukkan bahwa buku teks bahasa Inggris lebih menjabarkan kompetensi bahasa Inggris secara umum dan tidak terarah pada jurusan TKJ itu sendiri.
\end{abstract}

Kata Kunci: Analisis Kebutuhan Siswa, Buku Teks Bahasa Inggris, SMK.

\begin{abstract}
Learning English in Vocational High School (SMK) is different from teaching English in Senior High School. In SMK, the orientation is to prepare students to be able to take part in the work field. Consequently, English teachers in vocational school are expected to have the ability to analyze the needs of the students so that they can design an appropriate teaching-learning process. The aim of this study was to identify some factual information about the needs of vocational students in learning English, especially in the English-language skills (Listening, Speaking, Reading and Writing) and some of language components in English (Grammar \& Vocabulary), and to analyze the conformity between the content of English textbooks with the vocational students' needs. The subjects in this study were the vocational students and English textbooks, both SBC and Curriculum 2013 edition, of 7 (seven) SMK which organized the TKJ department in Bandung and Cimahi. The results showed that the needs of students towards learning English is to meet the academic professions and the future needs of the students, which involved the skills of the language and some of the language components. Whereas in the case of conformity between the content of the English textbooks and the vocational students' needs, it was found that the English textbooks was more focused on describing the English language competences generally and not directed to the Department of TKJ itself.
\end{abstract}

Keywords: Students'NeedsAnalysis, English Textbooks, Vocational School 


\section{A. PENDAHULUAN}

Pembelajaran bahasa Inggris di Sekolah Menengah Kejuruan (SMK) berbeda dengan pembelajaran bahasa Inggris di Sekolah Menengah Umum lainnya. Di SMK, orientasinya adalah mempersiapkan siswa agar mampu berkiprah di dunia kerja. Hal ini tertuang dalam UndangUndang no. 20 tahun 2003 mengenai Sistem Pendidikan Nasional tentang sistem Pendidikan Nasional. Sebelumnya, ada Peraturan Pemerintah No.29/1990 tentang Pendidikan Menengah Pasal 1 ayat 3 yang menyatakan bahwa pendidikan kejuruan merupakan pendidikan yang mengutamakan pengembangan kemampuan siswa dalam untuk memiliki keterampilan khusus. Dengan demikian, mengajar bahasa Inggris di sekolah kejuruan dikategorikan sebagai English for Specific Purposes (ESP/Bahasa Inggris untuk Keperluan Khusus) karena tujuan dari belajar bahasa Inggris adalah spesifik, disesuaikan dengan Jurusan yang mereka ambil.

Di dalam pembelajarannya, materi bahasa Inggris diharapkan dapat memenuhi kebutuhan siswa akan bahasa Inggris yang sesuai dengan yang dibutuhkan siswa di masing-masing Jurusan. Kebutuhan di masing-masing jurusan ini patut dicermati karena bahasa Inggris yang digunakan dalam berbicara dan menulis berbeda dari satu konteks ke konteks lainnya (Hutchinson \& Waters dan Waters s, 1986). Kebutuhan siswa dalam pelajaran Bahasa Inggris dalam bidang tertentu dapat digali melalui analisis kebutuhan (Richards , 2001). Diperlukan adanya analisis yang digunakan untuk mengembangkan tujuan dan isi; juga data untuk mengevaluasi program yang ada (Richards dalam Nunan, 1988).

Melihat fenomena di atas, guru-guru Bahasa Inggris di SMK diharapkan memiliki kemampuan dalam menganalisis kebutuhan siswa sehingga mereka dapat merancang proses belajar- mengajar yang sesuai, terutama dalam keterampilan berbahasa Inggris (Listening, Speaking, Reading, dan Writing) dan komponen dalam bahasa Inggris (Grammar \& Vocabulary). Dengan kata lain, pembelajaran bahasa yang efektif dapat dicapai bila guru menyadari kebutuhan siswa berdasarkan kebutuhan, kemampuan, potensi, dan preferensi dalam memenuhi kebutuhan (Bada \& Okan, 2000). Pernyataan serupa juga datang dari Brindley (1989, seperti dikutip dalam Bada \& Okan, 2000), bahwa materi pelajaran Bahasa Inggris harus mencakup apa yang dibutuhkan siswa dan apa yang harus diberikan guru. Kebutuhan tersebut dapat tercermin dalam silabus.

Hal ini telah menjadi isu penting dalam diskusi di bidang pendidikan. Dalam merancang silabus, perlu diketahui apa yang siswa perlukan dan bagaimana memilih buku ajar. Hal ini sesuai dengan tujuan rancangan silabus yang sesuai dengan kebutuhan siswa.Seperti yang dinyatakan oleh Nunan (2001), "Syllabus is a specification of what is to be taught in a language program and the order in which it is to be taught" (spesifikasi apa yang akan diajarkan dalam program bahasa dan urutan yang harus diajarkan"). Selain itu, Kavaliauskiene (2003) mengatakan bahwa keputusan guru dalam pengajaran bahasa tergantung pada berbagai faktor, di antaranya yang paling penting adalah tujuan dari pelajaran bahasa Inggris dan kebutuhan masing-masing siswa berdasarkan metode dan sikap terhadap pentingnya berbagai keterampilan bahasa.

Berdasarkan pengamatan di beberapa sekolah kejuruan, Peneliti berpendapat bahwa meskipun beberapa guru mengetahui kebutuhan siswa, namun kesempatan untuk memilih kegiatan dalam pelajaran Bahasa Inggris yang sesuai untuk siswa tidak cukup memadai. Tidak semua guru mampu menerapkan variasi dalam proses belajar mengajar yang disesuaikan dengan kebutuhan dan persepsi siswa. Kondisi ini sejalan dengan hasil penelitian Barkhuizen (1998) bahwa persepsi guru dan siswa sangat berbeda.Hal ini diperkuat oleh Dr Imam Ghozali, seorang dosen ahli bidang linguistik Universitas Sarjana Wiyata Yogyakarta, bahwa buku teks bahasa Inggris SMK tidak sesuai dengan kompetensi yang diperlukan. Akibatnya banyak siswa SMK yang akhirnya kesulitan mengembangkan kompetensi, apalagi kemampuan berkomunikasi yang dibutuhkan di dunia industri (www.suaramerdeka.com, 2011).

Dari uraian di atas, tampak bahwa kebutuhan siswa dalam belajar bahasa merupakan salah satu aspek penting dalam menciptakan proses pembelajaran bahasa yang efektif bagi siswa SMK. Peneliti mengkaji lebih lanjut mengenai hal ini dengan melakukan penelitian berjudul "Analisis Kebutuhan Siswa dalam Materi Buku Teks Bahasa Inggris Tingkat SMK".

Rumusan masalah dalam penelitian ini, yaitu:

a. Apakah kebutuhan siswa SMK terhadap pembelajaran bahasa Inggris? 
b. Bagaimanakah kesesuaian antara kandungan dalam buku teks pelajaran Bahasa Inggris dengan siswa di SMK dari segi kebutuhan siswa (students' needs)?

Tujuan dari penelitian, sebagai berikut:

1) mengidentifikasi beberapa informasi faktual mengenai kebutuhan siswa SMK dalam pembelajaran bahasa Inggris.

2) menganalisis kesesuaian antara kandungan dalam buku teks pelajaran Bahasa Inggris dengan siswa di SMK dari segi kebutuhan siswa (students' needs).

\section{B. KAJIAN TEORI DAN METODE}

\section{Kajian Teori}

\section{a. Needs Analysis (Analisis Kebutuhan)}

Salah satu asumsi dasar pengembangan kurikulum adalah bahwa semua hal yang berkaitan dengan pembelajaran bahasa Inggris harus didasarkan pada analisis kebutuhan siswa.Richards s (2001) mengatakan bahwa prosedur yang digunakan untuk mengumpulkan informasi tentang kebutuhan siswa dikenal sebagai Needs Analysis (analisis kebutuhan). Salah satu jenis analisis kebutuhan adalah student's need analysis (analisis pembelajar) (Nunan, 2001).Analisis pembelajar didasarkan pada informasi tentang siswa.Informasi ini dapat digunakan oleh guru dalam membuat silabus dan metodologi sehingga mereka lebih sesuai dengan karakteristik siswa.

Dalam student's need analysis atau analisis pembelajar, ada dua jenis informasi yang dapat diperoleh, yaitu: informasi obyektif dan informasi subjektif. Informasi obyektif adalah informasi faktual yang tidak memperhatikan sikap dan pandangan siswa, misalnya usia, kebangsaan, bahasa sehari-hari, dll , Sementara informasi subjektif mencerminkan prioritas dan persepsi siswa. Ini mencakup informasi tentang mengapa pelajar ingin belajar bahasa lain (baca: Bahasa Inggris), dan tugas-tugas di kelas, serta kegiatan yang lebih disukai siswa. Dengan kata lain, informasi subjektif mencerminkan prioritas dan persepsi siswa tentang apa yang harus diajarkan dan bagaimana harus diajarkan. Menurut Nunan (2001), informasi tersebut seringkali menggambarkan persepsi gaya belajar siswa.

Lebih lanjut, analisis kebutuhan belajar siswa diperlukan agar guru dapat lebih memahami minat siswa dan memulai proses desain pembelajaran dengan informasi yang didapat dari siswa, sehingga kebutuhan siswa dapat lebih terpenuhi (Hutchinson \& Waters, 1987).

\section{b. Analisis Kebutuhan dalam bahasa Inggris untuk Keperluan Khusus (ESP)}

Pembelajaran bahasa Inggris di sekolah-sekolah kejuruan dikategorikan sebagai Bahasa Inggris untuk Keperluan Khusus (English for Specific Purposes/ESP) karena tujuan dari belajar bahasa Inggris adalah tergantung pada jurusan/bidang siswa. Pengajaran bahasa Inggris sebagai bahasa asing (English as a Foreign Language/EFL) atau bahasa kedua (English as a Second Language/ESL) dibagi menjadi beberapa cabang (Hutchinson \& Waters, 1987).Dalam hal ini perlu dibedakan antara "General English" (bahasa Inggris umum) dan "ESP" (bahasa Inggris untuk keperluan khusus).

Mereka mendefinisikan ESP sebagai suatu pendekatan dalam pembelajaran bahasa, dimana semua keputusan tentang materi/konten dan metode didasarkan pada alasan siswa untuk belajar.ESP dilaksanakan dengan menyesuaikan dengan kebutuhan siswa.Kegiatan belajarmengajar biasanya terfokus pada siswa sebagai pertimbangan utama dalam pembelajaran. Dengan kata lain, ajaran ESP menerapkan pendekatan berpusat pada siswa. Kebutuhan siswa didefinisikan dalam hal mengapa mereka ingin belajar bahasa Inggris dan jenis bahasa Inggris yang mereka akan menggunakan atau bermanfaat bagi masa depan mereka.

Robinson, seperti dikutip dalam Supono (1991), mengusulkan empat hal penting terkait dengan ESP, yaitu:

1) ESP itu berorientasi pada tujuan,

2) Mahasiswa ESP biasanya orang dewasa yang belajar bahasa Inggris, baik sebagai bahasa kedua atau bahasa asing,

3) Mayoritas siswa ESP bukan pemula yang baru belajar bahasa Inggris,

4) Guru ESP tidak hanya mengajar tetapi juga bertindak sebagai penulis materi.

Untuk mengetahui materi yang baik dan sesuai dengan kebutuhan siswa perlu adanya suatu evaluasi terhadap materi ajar. Proses evaluasi terhadap materi ajar ESP menurut Hutchinson \& Waters (1987) mencakup langkah-langkah berikut ini: 
a) Menetapkan kritera:

(1) Apa dasar pemilihan materi?

(2) Kriteria mana yang lebih penting?

b) Analisis subjektif:

Bagaimanakah realisasi kriteria dalam pelajaran?

c) Analisis objektif:

Bagaimanakan realisasi materi yang dievaluasi menurut kriteria?

d) Pencocokan:

Sejauh mana kecocokan materi dengan kebutuhan yang dicari?

Dalam menetapkan kriteria, perlu disesuaikan antara materi dengan kebutuhan yang diperoleh dari lapangan yang menjawab tentang kebutuhan topik dan keterampilan berbahasa (skill). Sedangkan materi yang diperoleh melalui buku teks akan menjawab keterampilan berbahasa seperti apa yang diajarkan. Kedua sumber tersebut kemudian dicocokkan.

\section{c. Desain Silabus Pembelajaran Bahasa}

Merancang silabus merupakan salah satu rangkaian kegiatan dalam pengembangan kurikulum. Pernyataan ini sejalan dengan Lim (1988) sebagaimana dikutip dalam Richards (2001). Ia mengatakan bahwa pengembangan kurikulum meliputi analisis kebutuhan, penetapan tujuan, desain silabus, desain material, desain program bahasa, persiapan guru, pelaksanaan program di sekolah, pemantauan dan evaluasi.

Terkait dengan silabus, silabus dalam ESP dipengaruhi oleh tiga faktor (Hutchinson \& Waters dan Waters s, 1987), yaitu: teori bahasa, teori belajar, dan analisis kebutuhan. Penelitian ini akan difokuskan pada faktor ketiga, yaitu analisis kebutuhan yang menganalisis karakteristik siswa dan situasi belajarnya. Dalam mengembangkan silabus ESP, seorang perancang silabus harus menganalisis kebutuhan siswa dalam belajar bahasa Inggris.Selain itu, teknik dan prosedur untuk mengumpulkan informasi ini digunakan dalam merancang silabus yang disebut sebagai analisis kebutuhan (Nunan, 2001; Richards s, 2001; Brown, 1995).

Badan Standar Nasional Pendidikan/BSNP (2006) juga menetapkan 8 (delapan) prinsip yang harus dipertimbangkan ketika mengembangkan silabus, sebagai berikut:
1) Ilmiah

Materi ajar dan kegiatan yang tercantum dalam silabus harus benar dan dapat dipertanggungjawabkan secara ilmiah.

2) Relevan

Cakupan, kedalaman, dan tingkat kesulitan serta perintah dalam silabus harus relevan dengan perkembangan fisik, intelektual, sosial, ekonomi, dan spiritual siswa.

3) Sistematis

Komponen dalam silabus harus saling terkait untuk mencapai standar kompetensi yang ditentukan.

4) Konsisten

Harus ada konsistensi antara kompetensi, indikator, topik utama, kegiatan belajar, sumber belajar, dan sistem penilaian.

5) Cukup

Cakupan indikator, materi pokok, kegiatan pembelajaran, sumber belajar, dan sistem penilaian harus cukup untuk mencapai kompetensi dasar.

6) Aktual dan kontekstual

Cakupan indikator, materi utama, kegiatan belajar, sumber belajar, dan sistem penilaian harus sejalan dengan perkembangan ilmu pengetahuan, teknologi, dan seni yang terjadi dalam kehidupan nyata.

7) Fleksibel

Semua komponen dalam silabus harus dapat mengakomodir kebutuhan siswa, guru, dan perubahan dinamis yang mungkin terjadi baik di sekolah maupun tuntutan masyarakat.

8) Lengkap

Komponen silabus mencakup tiga domain kompetensi: kognitif, afektif, dan psikomotor.

\section{Metode Penelitian}

Penelitian ini menggunakan metode deskriptif. Metode deskriptif adalah metode yang paling umum digunakan dalam penelitian pendidikan (Burns, 2000).Data dikumpulkan melalui kuesioner pada guru, wawancara pada siswa dan guru, serta kajian pustaka.

Beberapa prosedur akan diterapkan untuk pelaksanaan penelitian ini. Pertama, peneliti menentukan latar belakang penelitian.Dari latar belakang, masalah dan tujuan penelitian diidentifikasi.Kemudian, literatur, yang mendasari topik yang sedang dibahas dalam masalah diidentifikasi.Selanjutnya, data dan literatur dianalisis dan diinterpretasikan.Interpretasi dilakukan dengan menggunakan metode 
deskriptif.Akhirnya, kesimpulan dan rekomendasi diambil berdasarkan temuan.

Kegiatan survey awal ke beberapa SMK dilaksanakan pada tanggal 13-16 Juli 2015 untuk memperoleh data jurusn yang paling banyak diminati siswa.Lalu pada tanggal 10-13 Agustus dilakukan pengambilan data awal ke sekolah, melalui kuesioner untuk guru bahasa Inggris lalu untuk memperoleh pemahaman yang lebih mendalam maka dilakukan wawancara pada siswa dan guru terkait.Data kemudian dianalisa, dilakukan kajian pustaka, untuk menjawab pertanyaan penelitian.

Subyek penelitian ini adalah siswa dan buku buku pelajaran bahasa Inggris untuk SMK,baik edisi KTSP maupun edisi Kurikulum 2013, di daerah Bandung dan Cimahi. Penelitian ini difokuskan kepada siswa dan buku Bahasa Inggris yang digunakan di SMK jurusan TKJ. Jurusan TKJ adalah suatu jurusan yang terdapat di SMK yang mempelajari seluk beluk komputer dan jaringannya seperti cara membuat PC, instalasi OS (Sistem Operasi), membuat web dan masih banyak lagi. Alasan pemilihan subjek penelitian ini TKJ karena saat ini TKJ adalah jurusan yang paling diminati untuk tingkat SMK.

Peneliti mengambil sampel 7 SMK di wilayah Bandung dan Cimahi, yaitu di wilayah Bandung dan Cimahi, yaitu SMKN 5 Bandung, SMKN 11 Bandung, SMK Informatika Bandung, SMK Medikacom Bandung, SMKN 1 Cimahi, SMK TI Pembangunan Cimahi, dan SMK Darussurur Cimahi.

Adapun buku teks bahasa Inggris yang diteliti adalah:

a. 1."Communication Builder: English for Vocational School" ditulis oleh Evi Kurniawan dan Arief Kurniawan, penerbit Departemen Pendidikan Nasional (Kurikulum 2013)

b. 2."English for SMK" ditulis oleh Maria Regina Dyah Pramesti dkk, penerbit Kementrian Pendidikan Nasional (Kurikulum 2013)

c. 3."Bahasa Inggris Berbasis Pendidikan Karakter" ditulis oleh Otong Setiawan Djuharie, penerbit Yrama Widya (Kurikulum 2013)

d. 4."Get Along with English" ditulis oleh Entin Sutinah dkk, penerbit Erlangga (Kurikulum KTSP) e. 5."Look Ahead: An English Course" ditulis oleh M.Sudarwati dan Eudia Grace, penerbit Erlangga (kurikulum KTSP)

\section{HASIL DAN PEMBAHASAN}

\section{a. Kebutuhan Siswa dalam Pembelajaran Bahasa Inggris}

Dalam hal kemampuan berbahasa Inggris, data menunjukkan bahwa hampir semua siswa di Jurusan TKJ yang menjadi sampel berpendapat bahwa berbicara dalam bahasa Inggris diperlukan karena akan membantu siswa dalam melakukan pekerjaan mereka. Namun, di sisi lain guru bahasa Inggris juga mengemukakan bahwa salah satu masalah dalam pembelajaran bahasa Inggris adalah keengganan siswa untuk terlibat aktif di kelas, mengemukakan ide mereka.

Hal ini juga diungkap oleh Harmer (2007) yang menyatakan bahwa tidak begitu mudah untuk membuat siswa berani berbicara di kelas.Masalah utama adalah keengganan yang dialami beberapa siswa untuk berbicara dan berpartisipasi aktif di kelas. Hal ini sejalan dengan Beccy (2013) yang menyatakan bahwa faktor utama yang membuat siswa enggan berkontribusi di dalam kelas karena mereka takut kehilangan muka atau menjadi bahan lelucon di depan teman-teman sekelas mereka.

Sedangkan dalam hal komponen bahasa, data menunjukkan bahwa sebagian besar siswa percaya bahwa tata bahasa adalah sesuatu yang diperlukan untuk dikuasai dalam belajar bahasa Inggris. Namun, ada beberapa siswa yang merasa bahwa tata bahasa bukanlah sesuatu yang dibutuhkan. Alasannya terungkap dari wawancara ketika beberapa diantara mereka ditanya tentang pertanyaan yang sama. Dari wawancara, alasan tidak memilih tata bahasa Inggris sebagai hal yang dibutuhkan adalah dari pengalaman siswa saat Praktek Kerja Industri. Menurut mereka saat praktek tidak sering berurusan dengan tata bahasa Inggris, sehingga merekamerasabahwa pada saat itu, tata bahasa Inggris tidak benar-benar diperlukan untuk dikuasai.

Fenomena ini didukung McWhorter (2012) menyatakan bahwa untuk banyak profesi, tata bahasa bukan merupakan keterampilan penting. Dengan kata lain, tata bahasa mungkin tidak begitu penting untuk pekerjaan tertentu. Di sisi lain, dalam hal kosa kata Bahasa Inggris kebanyakan dari mereka menyatakan mereka perlu menguasai 
kosakata yang cukup untuk melakukan pekerjaanyang berhubungan dengan bidang mereka. Mereka berpendapa tbahwa mengetahui banyak kosakata dalam Bahasa Inggris dapat membantu mereka dalam melakukan pekerjaan. Hal inisejalan dengan pendapat Alexander(2013) bahwa pemahaman meningkat ketika seseorang menguasai berbagai kosakata. Kosakata meningkatkan kemampuan komunikasi, kompetensi akademik, bahkan kemampuan sosial mereka.

Hal tersebut di atas, juga didukung oleh temuan berdasarkan interview yang menyatakan bahwa kebutuhan siswa SMK jurusan TKJ dalam bahasa Inggris adalah yang banyak mengenalkan dunia industri, kemampuan berkomunikasi di lingkungan umum dan industri, serta banyak mengenalkan vocabulary terutama kepada istilah, prosedur, serta kompetensi SMK jurusan Teknik Komputer Jaringan pada umumnya.

Temuan di atas menunjukkan bahwa harapan siswa dan situasi pembelajaran dapat membangun pembelajaran bahasa Inggris dalam memenuhi kebutuhan peserta didik secara efektif terutama kebutuhan terhadap pembelajaran bahasa Inggris untuk memenuhi kebutuhan profesi akademik dan masa depan siswa, yang melibatkan kemampuan bahasa dan beberapa komponen bahasa.

\section{b. KebutuhanSiswa dalam Buku Teks}

Hasil analisa dari hasil buku teks berdasarkan teori BNSP menunjukkan bahwa: Buku "Get Along with English" memiliki kelayakan sebesar 86,2\%. Berikutnya, buku "Bahasa Inggris Berbasis Pendidikan Karakter" dan buku "Communication Builder: English for SMK" memiliki kelayakan sebesar 83\%. Kemudian, buku "English for SMK" memiliki kelayakan sebesar 75\%. Sedangkan buku "Look Ahead: An English Course" memiliki kelayakan sebesar $69,4 \%$.

Hal ini menunjukkan bahwa:

1) Hubungan atau kesesuaian antara buku teks bahan ajar serta kompetensi bahasa Inggris SMK jurusan TKJ yang diharapkan adalah kurang sesuai dengan skor total 4 dari total nilai 8.

2) Meskipun tidak adanya kekhususan, secara umum SK KD dalam buku acuan sudah cukup memenuhi dan melatih language skills siswa. Namun perlu diperhatikan bahwa kebanyakan guru menanggapi bahwa 4 language skills tersebut tidak diperhatikan dengan seksama karena umumnya lebih mengandalkan kemampuan reading dan writing saja, dan itu yang umumnya lebih sering muncul dalam buku acuan. Buku belum memenuhi kompetensi 4 language skills karena terlalu banyak memasukkan unsur teks, sebaiknya language skills yang lain juga diberikan porsi latihan yang banyak agar lebih seimbang. Penting juga agar buku dibuat lebih menarik dengan gambar yang berwarna sehingga siswa lebih senang dan bersemangat saat menggunakan buku tersebut.

3) Berdasarkan wawancara dengan 7 orang guru SMK yang merupakan sampel penelitian ini, buku yang digunakan di SMK belum sepenuhnya memuat materi terkait dengan bidang siswa, yaitu Teknik Komputer Jaringan. Oleh karena itu, 2 orang guru menambahkan materi Reading yang terkait dari berbagai sumber. Sedangkan 5 guru lainnya membiarkan tanpa materi atau pengayaan lainnya.

Dapat dijabarkan bahwa kebutuhan siswa SMK jurusan Teknik Komputer Jaringan yang terkait dengan pembelajaran bahasa Inggris adalah yang sesuai dengan SK KD yang ada serta sesuai dengan silabus yang dipelajari dalam Teknik Komputer Jaringan.

Berdasarkan hasil interview dinyatakan bahwa kebutuhan siswa SMK jurusan TKJ dalam bahasa Inggris adalah yang banyak mengenalkan dunia industri, kemampuan berkomunikasi di lingkungan umum dan industri, serta banyak mengenalkan vocabulary terutama kepada istilah, prosedur, serta kompetensi SMK jurusan Teknik Komputer Jaringan pada umumnya.

Uraian di atas menunjukkan bahwa harapan siswa dan situasi pembelajaran dapat membangun pembelajaran bahasa Inggris dalam memenuhi kebutuhan peserta didik secara efektif. Di antara isu yang diangkat dari siswa adalah kebutuhan terhadap pembelajaran bahasa Inggris untuk memenuhi kebutuhan profesi akademik dan masa depan siswa, yang melibatkan kemampuan bahasa dan beberapa komponen bahasa. Temuan ini mendukung penelitian sebelumnya mengenai kebutuhan siswa, seperti yang dilakukan oleh Bada dan Okan, 2008; Barkhuizen, 1998; Berkowitz dan Nagy, 2013; dan Kavaliauskiene, 2003. 
Dalam hal mengakomodir kebutuhan siswa dalam buku teks, siswa SMK jurusan TKJ cenderung memiliki motivasi yang tinggi pada profesi/bidang mereka. Kelima buku mencoba untuk memenuhi kebutuhan siswa tentang kemungkinan profesi masa depan mereka, seperti Looking for A Job, Talking on The Phone, Life at Work, How do You Operate This Machine (seperti yang terdapat dalam buku karangan Kurniawan dan Kurniawan (2008); Pramesti, Pramono, dan Suherman (2008); Sutinah, et al (2010)). Namun demikian, tidak semua buku membahas topik yang sama.

Dengan kata lain, kesesuaian antara kandungan dalam buku teks bahasa Inggris dengan jurusan siswa di SMK TKJ dari segi students needs menunjukkan bahwa buku teks bahasa Ingris serta SK KD yang diformulasikan oleh pemerintah lebih menjabarkan kompetensi bahasa Inggris secara umum dan tidak terarah pada jurusan TKJ itu sendiri.

\section{KESIMPULAN}

Penelitian ini dilakukan untuk mencari informasi faktual mengenai kebutuhan siswa SMK jurusan TKJ, dan untuk mengetahui cakupan buku teks yang digunakan dalam mengakomodir kebutuhan siswa SMK dalam pembelajaran Bahasa Inggris.

Berdasarkan hasil temuan, dari penelitian ini tampak bahwa:

1. Kebutuhan siswa SMK jurusan Teknik Komputer Jaringan terhadap yang terkait dengan pembelajaran bahasa Inggris adalah yang sesuai dengan SK KD yang ada serta sesuai dengan silabus yang dipelajari dalam Teknik Komputer Jaringan. Akan tetapi, berdasarkan hasil interview dinyatakan bahwa kebutuhan siswa SMK jurusan TKJ dalam bahasa Inggris adalah yang banyak mengenalkan dunia industri, kemampuan berkomunikasi di lingkungan umum dan industri, serta banyak mengenalkan vocabulary terutama kepada istilah, prosedur, serta kompetensi SMK jurusan Teknik Komputer Jaringan pada umumnya.

2. Kesesuaian antara kandungan dalam buku teks bahasa Inggris dengan jurusan siswa di SMK TKJ dari segi students needs adalah buku teks bahasa Ingris serta SK KD yang diformulasikan oleh pemerintah lebih menjabarkan kompetensi bahasa Inggris secara umum dan tidak terarah pada jurusan TKJ itu sendiri. Hal tersebut kemungkinan merupakan refleksi dari Standard Kompetensi itu sendiri, yaitu Berkomunikasi dalam bahasa Inggris di tingkat Novice (Pemula).Berkomunikasi pada tingkat pemula berarti bahwa komunikasi memerlukan kompetensi dasar bahasa Inggris. Materi dalam komunikasi umum, misalnya: salam, meninggalkan pesan, mengungkapkan perasaan, dan mengekspresikan penyesalan menunjukkan bahwa materi pelajaran belum ditentukan berdasarkan jurusan tertentu di sekolah kejuruan (SMK).

\section{E. DAFTAR PUSTAKA}

Alexander, F. (2013). Understanding Vocabulary.[Online]. Available at: www.scholastic.com. [December 1, 2013]

Allwright, R. (1979). Language Learning Through Communication Practice. In Brumfit, C., and Johnson, K. (eds.) The Communicative Approach to Language Teaching. Oxford: Oxford University Press.

Bada, E. \& Okan, Z. (2000).Student's Language Learning Preferences. TESL Journal Vol. 4 No.3. [Online]. Available at: http://www.writing.berkeley.edu/TESLEJ/ej15/a1.html.

Badan Standar Nasional Pendidikan/BSNP .(2006). Barkhuizen, G.P. (1998). Discovering Learners' Perceptions of ESL classroom Teaching/Learning Activities in a South African Context.TESOL Quarterly, 32, $85-108$.

Beare, K. (2011). How to Choose a Coursebook and Other Classroom Materials.[Online]. Available http://esl.about.com/cs/teachingresources $/ \mathrm{ht} /$ coursebook.html. [October 27, 2011]

Beccy. (2013). Why Language Students are Reluctant to Speak?[Online]. Available at: www.kanzilingua.com. [December 2, 2013]

Berkowitz, B. \& Nagy, J. (2013).Conducting Needs Assessment Surveys.The Community Tool Box. Available Online at: http://ctb.ku.edu/. Current as of April 30, 2013.

Bertin, B. (2003). How to Use Coursebooks.[Online]. Available at: http://www.univirtual.it .Current as of October 22, 2011. 
Brown, H.D. (2001). Teaching By Principles: An Introduction Approach to Language Pedagogy. New York: A Pearson Education Company.

Brown, J.D. (1995). The Elements of Language Curriculum. A Systematic . Approach to Program Development. University of Hawaii at Manoa. Massachusetts: Heinle $\&$ Heinle Publishers.

Burgen, W.A.,and Amundson, N.E. (1998). Models of Adolescents Transitions.[Online]. Available at: http://www.ecap.crc.illinois.edu. [March 8, 2013]

Burns, R. (2000). Introduction to Research Methods: Fourth Edition. San Fransisco: Addison Wesley Longman, Inc.

Harmer, J. (2001).The Practice of English Language Teaching. Edinburgh: Pearson Education.

Harmer, J. (2002).The Practice of English Language Teaching. $3^{\text {rd }}$ ed. Longman.

Harmer, J. (2007).How to Teach English.Longman. England.

Hornby, A.S. (1995). Oxford Advanced Learners: Dictionary of Current English. Oxford University Press.

Hutchinson, T., and Waters, A.( 1987). English for Specific Purposes: A Learner Centered Approach. Cambridge University Press.

Kavaliauskiene, G. (2003). English for Specific Purposes: Learner's Preferences and Attitudes. Journal of Language and Learning Vol. 1 No. 1.[Online]. Available at: http://www.shakespeare.uk. net/journal/jlearn/1_1/kavaliauskiene_lea rn1_1.html

Kridalaksana, H. (1993). Kamus Lingusitik. Jakarta: Gramedia.

Kruise, A.F. (1987). Methodology in TESOL; A Book of Reading.New York: Newbury House Publisher.

McWhorter, J. (2011). What Language Is (and what it isn't and what it could be). [Online]. Available at: http://opinionator.blogs.nytimes.com.

Nunan, D. (1988). The Learner-Centred Curriculum. Britain: Cambridge University Press.

Nunan, D. (2001). Syllabus Design. Oxford: Oxford University Press.

Richards, J.C. (2001). Curriculum Development in Language Teaching. UK: Cambridge University Press.
Robinson, P. C. (1989). An overview of English for specific purposes. In $\mathrm{H}$. Coleman (Ed.), Working with language: A multidisciplinary consideration of language use in work contexts(pp. 395428). Berlin: Mouton de Gruyter.

Widdowson, H.G. (1983). Learning Purpose and Language Use. Oxford: Oxford University Press.

Yochanna, M. (2011).Choosing a Course Book.[Online]. Available at: http://www.etni.org.il/etnirag/issue4/miri _yochanna.html [September 30, 2011] www.suaramerdeka.com.2011. Buku Teks Bahasa Inggris SMK Tidak Sesuai Kompetens.http://suaramerdeka.com/v1/i ndex.php/read/news/2011/06/15/88404. 